\title{
0 lugar do pedagógico nos filmes feitos para crianças
}

Fernanda Omelczuk Walter *

http://dx.doi.org/10.1590/0103-7307201507809

\section{Resumo}

0 artigo pensa, sob o ponto de vista pedagógico, as produções cinematográficas endereçadas às crianças. 0 que motiva cineastas a produzirem obras cinematográficas para as crianças? 0 que as crianças aprendem quando veem um filme? Todo filme * Faculdade de Educação da Universidade Federal do Rio de Janeiro, Rio de Janeiro, RJ, Brasil. fernandaow@gmail.com infantil é um filme educativo? 0 que caracteriza um filme educativo? Para trabalhar essas questões, o texto alinha-se com as ideias de Virgínia Kastrup sobre uma "política cognitiva da invenção" e defende a necessidade de estabelecer uma nova política cognitiva para a educação, para a aprendizagem e para a relação da criança com o cinema. Em diálogo com o crítico de cinema Alain Bergala, com o filósofo Walter Benjamin e outros, o texto vai em busca de parâmetros que possam auxiliar a construção de uma linguagem fílmica para as crianças, em consonância com essa nova política cognitiva.

Palavras-chave: cinema e educação, cinema educativo, filmes infantis, aprendizagem 


\title{
The place of the pedagogical in the films made for children
}

\begin{abstract}
The article discusses, from a pedagogical point of view, the film productions addressed to children. What children learn when they watch a film? What motivates filmmakers to produce films for children? Every child film is educational? What characterizes an educational film? Based on Virginia Kastrup's ideas on a "cognitive invention policy", the text advocates the need to establish a new cognitive policy for education, for learning and for children relationship with cinema. In dialogue with film critic Alain Bergala and philosopher Walter Benjamin, among others, the article discusses parameters that can facilitate the construction of a filmic language for children in line with this proposed cognitive policy.
\end{abstract}

Keywords: theater and education, educational cinema, children's films, learning 


\section{Introdução}

O objetivo deste artigo é acompanhar a trajetória do pedagógico nas produções cinematográficas feitas para as crianças e sugerir novas proposições. Com a ajuda do pensamento de Kastrup $(2005,2007)$ sobre as políticas cognitivas, veremos que o cinema educativo respondeu prioritariamente à "política da recognição", em que a aprendizagem se define na obtenção de determinados comportamentos e informações transmitidos pelo filme. Acompanhando as reflexões de Benjamin (2002a), notaremos que essa mesma política será encontrada na literatura e no cinema infantil.

0 texto defende o desenvolvimento de uma nova política cognitiva - chamada por Kastrup de "política cognitiva de invenção" - para a educação, para a aprendizagem e para a relação da criança com o cinema. Com a ajuda do pensamento de Bergala (2008), Fresquet $(2009,2013)$ e Leandro $(2001,2010)$, buscamos parâmetros que possam nos auxiliar a identificar uma linguagem fílmica para as crianças, em consonância com essa nova política cognitiva.

\section{0 pedagógico no cinema educativo}

Desde seu nascimento no final do século XIX, o cinema atraiu olhares esperançosos e desconfiados de seu poder de educação, persuasão e domínio das massas. Na década de 1920, passado pouco mais de um quarto de século do surgimento do cinema, professores e educadores brasileiros, certos da influência que os filmes exerciam sobre o comportamento, começaram a indicar o cinema para auxiliar na educação, na higienização, na divulgação dos valores nacionais e na formação de uma nação, ideais alinhados com a política da Era Vargas, que pensava o cinema como "o livro de imagens luminosas"1, demarcando prontamente o viés didático e instrucional que os filmes deveriam ter.

A educação do povo era prioridade nesse período histórico em que o País se consolidava como República, e o cinema, recém-nascido, era visto como um instrumento capaz de organizar e potencializar o papel do professor. Segundo Carrière (2006), a velocidade com que o cinema se desenvolveu e se transformou criou um novo gênero de memória e gerou um frenesi pelo sonho de uma linguagem universal.

Apostava-se que o cinema levaria para as crianças as imagens mais próximas da realidade, cabendo ao professor ordenar e elucidar os acontecimentos exibidos na tela, orientando a percepção do aluno. 0 mestre deveria dirigir a recepção do filme para o que nele é visto e ouvido. cinema em seu discurso para os representantes da Associação dos Produtores Cinematográficos em 1934. 
Em 1931, Joaquin Canuto Mendes de Almeida, um entusiasmado jovem cineasta, publicou o livro Cinema contra cinema, em que defende as benesses do uso do cinema na educação e orienta sobre como trabalhar as imagens em movimento em sala de aula. 0 poder das imagens do cinema para o bem ou para o mal sempre foi uma preocupação, e Cinema contra cinema se apresentou como uma resistência ao "mau cinema" - o cinema mercantil -, conforme chamava Canuto Mendes.

Em resumo, Canuto Mendes, em seu livro deixava claro, já a partir do seu título, a preocupação com o "perigo" representado pelo mau cinema [ênfase adicionada]. Porque no fundo, apesar de nutrir uma enorme e reconhecida admiração pela "energia" do cinema e pela força educativa, colocava apenas uma condição essencial [ênfase adicionada]: “era necessário primeiro educar o próprio cinema para que o mesmo pudesse, então, educar" [ênfase no original] (Saliba, 2003, p.149).

Tratava-se, portanto, de escolher e fazer o cinema certo, um certo cinema, já que determinadas imagens, modelos, cenas, eram considerados prejudiciais à formação dos jovens e das crianças. 0 mundo todo se preocupava com os efeitos deletérios do cinema, e no Brasil não foi diferente (Saliba, 2003).

Seguindo esse movimento de escala global, o Decreto 21.240/1932 formalizou a censura das obras cinematográficas, assegurando alguns critérios pedagógicos. A definição seguinte, acerca do cinema educativo, foi publicada na primeira edição da Revista Nacional de Educação, cujo editor, Edgar Roquette-Pinto, dirigia a comissão responsável pela análise das obras nos anos 1930.

Serão considerados educativos, a juízo da Comissão, não só os filmes que tenham por objetivo intencional divulgar conhecimentos científicos, como aqueles cujo entrecho musical ou figurado se desenvolver em torno de motivos artísticos tendentes a revelar ao público os grandes aspectos da natureza ou da cultura (Revista Nacional de Educação, 1932, p.12, citado em Schvarzman, 2004, p.119).

Desde o princípio de suas atividades profissionais, Roquette-Pinto (1884-1954) esteve envolvido com a educação não escolar, seja na direção do Museu Nacional (1927-1936), onde organizou a primeira filmoteca para difusão do cinema educativo, ou na direção do Instituto Nacional de Cinema Educativo (INCE), no período de 
1937 - ano de sua fundação - até 1947. Alinhado aos propósitos da Escola Nova, ele defendia uma formação cultural que tinha na construção da identidade brasileira seu objetivo central. Assim, os filmes produzidos pelo INCE durante o período de sua liderança são fortemente marcados pela profusão de imagens nacionais que visavam divulgar a cultura brasileira.

Por atuar com iniciativas educacionais fora do âmbito escolar, a educação concebida por Roquette-Pinto suplantava as instruções e os conteúdos curriculares. 0 que estava em jogo, portanto, não era um cinema educativo estritamente instrucional ou disciplinar. Havia uma concepção de educação ampliada, com a consciência de que o cinema seria capaz de produzir uma subjetividade específica. E Roquette-Pinto confiava na possibilidade de construir, com o cinema, uma subjetividade nacional.

Se para os defensores da moral e da infância o campo oferecido pelo cinema estava partido entre imagens perniciosas ou imensas possibilidades edificantes, para Roquette-Pinto essa partilha se dava entre filmes estrangeiros que pouco valiam e os que nada valiam, ambos, porém, marcando presença no imaginário e enchendo olhos e corações de mensagens sobre outras culturas. Tratava-se, portanto, de fazer a distinção entre o que poderia ser ou não útil e verdadeiramente educativo para os brasileiros (Schvarzman, 2004, p.116).

Quais dispositivos tornavam, então, nessa época, o filme pedagógico?

Canuto Mendes dedicou boa parte de seu trabalho a orientar sobre como fazer o "bom cinema", aludindo especialmente a aspectos técnicos que poucos até então dominavam. Segundo Saliba (2003), ele via na objetiva o poder de apreensão da realidade visível e conferia duas funções independentes ao cinema: lúdica ou educativa - ou um cinema dramático e outro documental. Para a função educativa, as condições de montagem não foram exploradas por Canuto, isto é, a ação do próprio cineasta naquilo que escolhe filmar e editar não era tomada como um aspecto inventivo. Ele julgava que apenas o cinema dramático era subjetivo, fantasioso e dependia das escolhas do artista. Desaconselhava a abstração, a emoção e os sentimentos nos filmes, defendendo - e confiando nela - uma apreensão objetiva do real pelo aparelho.

Nas produções do INCE, a temática, o conteúdo e a mensagem transmitida eram o primeiro fator a ser considerado nos filmes. Para fortalecer a identidade nacional, divulgava-se o modo de ser do homem do campo, seus hábitos, sua música, seus costumes. Além disso, era importante que as imagens contribuíssem para a construção 
de uma consciência histórica, resgatando a origem do povo brasileiro e sua formação, construindo uma espécie de “orgulho nacional”. A maioria dos filmes de Humberto Mauro, principal cineasta do INCE, foi produzida com esse viés ${ }^{2}$.

De acordo com Pires (2011), para alcançar esses objetivos, alguns parâmetros de linguagem eram referências, no INCE, para a produção dos filmes. Eles tinham inspiração etnográfica e vínculo estreito com o documentário clássico: narração em off, imagens ilustrando o texto narrado, uma sequência de exibição didática, clara e racional.

Assim, com essa estética que garantia autoridade e realidade ao conteúdo das imagens, os filmes estavam a serviço do discurso pedagógico, ou melhor, de um certo discurso pedagógico. E que discurso é esse?

\section{Um diálogo entre o pedagógico na literatura e no cinema infantil}

A literatura, uma das irmãs mais velhas da sétima arte, deu à luz uma literatura infantil juntamente com o conceito de infância, gestado em meados do século XVI e no século XVII, quando a infância começou a ser entendida como uma etapa da vida com preocupações, investimentos e regulações específicas. Essa literatura surgiu, então, para exercer um papel formador e atender à ideologia da época: controle sobre a criança, adestramento de comportamentos, emoções e atitudes. Surgiram as histórias destinadas ao público infantil, com uma função pedagógica (Ariès, 1981; Benjamin, 2002a).

Mesmo com um grande intervalo de tempo, há intencionalidades convergentes entre esse cenário e o do cinema brasileiro nos anos 1930 no Brasil. Ambos, literatura e cinema, ao se dirigirem formalmente para a infância pela primeira vez, o fizeram com um intuito pedagógico claro, racionalista e didático: de um lado, o livro, ou o filme, com seus conteúdos; do outro, um sujeito a ser ensinado.

Ao escrever sobre essa determinada educação ética, implícita ou explícita nos livros infantis, Walter Benjamin (2002b) tece algumas reflexões. Ele questiona, a partir

2. Alguns dos principais filmes de Mauro na época do INCE: Da série As Brasilianas: Canções populares Chuáchá e Casinha pequenina (1945); Canções populares Azulão e Pinhal (1948); Aboio e Cantiga (1954); Engenhos e usinas (1955); Cantos de trabalho (1955); Manhã na roça e Carro de bois (1956). Meus oito anos (1956); O João de Barro (1956); São João Del Rei (1958); A velha a fiar (1964). da filosofia de Kant, a eficácia dessa pedagogia: “o ensino didático, com os seus fundamentos racionalistas e psicológicos, só pode atingir o empírico, o que está prescrito, mas jamais a atitude ética" (p.18). Segundo ele, esse tipo de ensino de moral não consegue ir além dos estímulos psicológicos, 
do reforço de comportamentos, da invocação por meio do elogio, pois uma verdadeira atitude ética pressupõe a formação de uma “vontade ética”- a qual é inverificável. Nenhum dado empírico é capaz de mensurá-la, visto que escapa da racionalidade presente no didatismo moral.

Assim, a tentativa de ensinar às crianças o respeito e a gratidão, por exemplo, contando durante a refeição que muitas pessoas trabalharam para que agora comêssemos, é para Benjamin inútil. Ele também questiona os livros infantis com um moralismo árido e desprovido de significado e afirma que as crianças se implicam mais com as imagens e os personagens do que com as ideias transmitidas. Complementa ainda que um nível mais profundo de envolvimento acontece quando a criança ultrapassa o pedagógico dos livros e se relaciona diretamente com o artista ilustrador. Esse, apesar de não trabalhar exclusivamente em função das crianças, fala-lhes muito com as imagens coloridas, convidando-as a mergulhar na fantasia que habitam. "O autêntico significado desses livros infantis, com seus singelos grafismos, está portanto muito distante da drasticidade embotada que levava a pedagogia racionalista a recomendá-los” (Benjamin, 2002 a, p. 66).

Portanto, para Benjamin, uma educação ética, que vise à formação da vontade ética, que supere a mera instrução, como compreendia Roquette-Pinto, deve abarcar também a irracionalidade. Não no sentido desumano, mas um não racional que pressupõe o sonho, a criação, a experiência, a nossa humanidade, e é imensurável pela ciência exata da educação. A tentativa bem-intencionada, objetiva e racionalista de educar as crianças em uma moral impressiona apenas aquelas que já conhecem, por exemplo, a gratidão e o respeito, vivenciando na ação esses sentimentos com outros, mas não causa efeito, se abordada em uma aula de moral ou em um livro.

A experiência social tem, portanto, para Benjamin, um valor fundamental na aprendizagem, como presumia seu contemporâneo, Vigotski (2003). Valor que se processa, segundo o psicólogo russo, pela imitação, atividade que permite à criança realizar o que está além do seu nível de desenvolvimento real. Em meio aos outros, "as crianças podem imitar uma variedade de ações que vão muito além dos limites de suas próprias capacidades" (p. 115), de modo que a aprendizagem social desperta processos internos de desenvolvimento latentes no sujeito, reconfigurando sua cognição.

Seguindo a direção de Vigotski (2003), o que Benjamin (2002b) parece levantar, ao dizer que "aula de moral" só servirá às crianças que já tenham aprendido esses sentimentos na vida social, é que essa natureza de intervenção atinge apenas os ní- 
veis de desenvolvimento reais, já estabilizados, isto é, aqueles que a criança já alcançou e não aqueles que ela ainda é capaz de aprender, que geram dúvidas, que se realizam com a ajuda de outros e com o auxílio de instrumentos (de trabalho, simbólicos e do pensamento).

Ao fornecerem às crianças um sistema fechado, cujo problema (uma moral, no caso) e sua solução estão dados durante toda narrativa da história, a aprendizagem limita-se como resolução de questões preexistentes colocadas por um outro. Não há conflito, não há problematização, não há problemas de verdade, porque se sabe de antemão a solução "correta”.

Assim, a substância educativa e moral dos livros não produz, na verdade, novas experiências; eles não colocam, de fato, novas questões, não geram dúvidas, não apresentam um universo desconhecido, não aproximam o sujeito da alteridade - apenas reforçam a aprendizagem como mera aquisição de conteúdos do mundo. BetteIheim (1980), pesquisador do universo maravilhoso na literatura, também se dizia insatisfeito com grande parte dos livros que buscam desenvolver a mente e a personalidade das crianças, ensinando habilidades e comportamentos, independentemente do significado íntimo que as histórias têm para elas; "estas estórias informam sem enriquecer”, dizia Bettelheim (1980, p.69).

É uma pedagogia que se concentra no acúmulo dos saberes transmitidos e atende ao que Kastrup (2005) chama de "política de recognição". Veremos agora o que isso significa e sua relação com a educação, a aprendizagem e o cinema infantil.

\section{Educação, aprendizagem e invenção}

As contribuições de Kastrup (2007), com as quais dialogaremos agora, são fruto de sua investigação sobre um quadro teórico que possibilite um verdadeiro estudo da "invenção" cognitiva: atividade criadora presente em todos os campos da vida cultural, artística, científica e técnica, função vital necessária da existência, como já assegurava Vigotski (2009). Seus estudos nos ajudarão a compreender o lugar do pedagógico nos livros e nos filmes infantis.

No livro A invenção de si e do mundo: uma introdução do tempo e do coletivo no estudo da cognição ${ }^{3}$, a autora apresenta com con-

3. A primeira edição do livro é de 1999, pela editora Papirus. Ele é uma reelaboração da tese de doutorado da autora, defendida em 1997 no Núcleo de Estudos e Pesquisas da Subjetividade da PUC-SP. sistência e profundidade os pressupostos de sua pesquisa que ilustraremos aqui. Tentaremos trazer as principais reflexões que atingem a educação, a 
aprendizagem e as repercussões, para pensarmos o cinema infantil, alertando, desde já, que a mudança paradigmática a que alude a autora merece um estudo particular e atencioso de toda sua obra.

Para começar, Kastrup (2007) coloca em cena a própria modernidade que, isolando um sujeito que aprende e um conteúdo a ser aprendido, toma o que se passa no meio isto é, a própria cognição -, como um sistema fechado, representacional, intermediário da relação homem-mundo, funcionando segundo leis gerais e estáveis, não propenso a transformações nem surpresas. Segundo a autora (Kastrup, 2007), o problema nesse modelo cognitivo é que ele não consegue responder a questão da invenção, que é o "movimento de problematização das formas cognitivas constituídas” (p.17).

A análise que Kastrup (2007) apresenta mostra que a psicologia, historicamente, colocou mal a questão da criatividade, restringindo-a à função de solução de problemas já dados pelo ambiente. A invenção, nesses casos, depende da representação adequada da situação e é uma operação da inteligência. No final das contas, tem-se um problema cuja solução já existe, e uma reestruturação do campo cognitivo é que permite sua descoberta. Segundo a autora, essa definição se conforma ao funcionamento do sistema cognitivo clássico, mas não dá conta de responder verdadeiramente sobre a potência da invenção. Se desse, levaria, na verdade, a uma revisão paradigmática do sistema cognitivo e do próprio ato de conhecer.

A invenção surge de um fundo arqueológico ou temporal, que impede a distinção a priori entre sujeito e objeto. Sujeito e objeto, pressupostos de toda teoria representacional da cognição, encontram-se abalados em seu caráter apriorístico, embora subsistam como efeitos da inventividade que opera em seus avessos. A cognição aparece, então, como um processo dotado de inventividade intrínseca, processo de diferenciação em relação a si mesma, o que responde pela criação de múltiplos e inéditos regimes de funcionamento. Ela é, assim, seu próprio invento (Kastrup, 2007, p.28).

Para Kastrup (2007), o projeto epistemológico da modernidade buscou condições invariantes para a inteligência, o que reduziu sobremaneira o campo das experiências cognitivas, além da real potencialidade inventiva da cognição e do próprio sujeito epistêmico. Para que esse conceito de cognição não fosse contrariado - o que causaria exatamente a mudança paradigmática (e política) que agora nos apresenta a autora -, privilegiaram-se certas experiências, “aquelas que permeiam nossa banalidade 
cotidiana, quando funcionamos conforme o senso comum ou, dito de outro modo, aquelas nas quais o funcionamento cognitivo revela-se estável” (pp.67-68). A autora denomina-as "experiências de recognição".

As experiências de recognição são, na verdade, a percepção, a representação, o reconhecimento das coisas e dos fatos e servem à adaptação do sujeito ao mundo. Tanto os estudos do gestaltismo quanto as pesquisas de Piaget reafirmam uma cognição estável, que, no final das contas, trata o conhecimento e a aprendizagem como um reconhecimento. Na opinião de Kastrup, isso se denuncia quando se constata a inexistência da temporalidade para compreender o funcionamento psicológico; e mesmo os estudos piagetianos que introduzem o tempo nas estruturas cognitivas o colocam apenas para o desenvolvimento progressivo e previsível de novas estruturas, que excluem a imprevisibilidade e a novidade - natureza e produtos intrínsecos da invenção.

Nessas considerações, acompanhando o raciocínio de Deleuze (citado em Kastrup, 2007, p.174) sobre o aprendiz, que é tão melhor quanto mais consegue permanecer em processo de aprendizagem, Kastrup aponta que, mesmo na aprendizagem, processo psicológico que melhor revela sua dimensão temporal e as transformações às quais a cognição está sujeita, a invenção foi reduzida à solução de problemas. Conforme ela mesma resume (Kastrup, 2007), “a aprendizagem é trabalhada e teorizada pela psicologia somente naquilo que ela possui de potência de repetição, e não de invenção. Submeter a aprendizagem à repetição é subsumi-la à forma da recognição" (p. 95).

De modo geral, a aprendizagem foi sempre tomada como aprendizagem de algo exterior ao organismo, existe um sujeito que aprende, um objeto a ser aprendido e uma cognição mediadora dessa relação. A nova política cognitiva que Kastrup nos apresenta - uma política da invenção - confere uma dimensão temporal ao processo da aprendizagem, permitindo que se assuma, assim, a contínua invenção de problemas por parte do sujeito, o que suplanta um sistema cognitivo como apenas mediador e estabelece novas formas de conhecer.

Segundo Deleuze (citado em Kastrup, 2007, p. 94), conhecer, ordinariamente, esteve relacionado a aprender algo com uma certa distância, mas, quando a aprendizagem é tomada a partir de sua temporalidade, ela pressupõe uma afetação; uma abertura; uma predisposição à inovação, ao desconhecido, ao movimento; um agenciamento com o “objeto" do conhecimento que é gerador de problemas, que é por, si só, inventivo. Vigotski (2003) já havia levantado a hipótese da transformação sofrida pelo próprio aparelho cognitivo com a aprendizagem. Pensando com Kastrup, quan- 
do ele afirma que o aprendizado resulta em desenvolvimento, podemos dizer que já anunciava que a aprendizagem geraria sempre uma nova cognição.

0 contato com a matéria se dá por meio de ações, não sendo intermediado por qualquer representação. Contato, portanto, inventivo, e não representativo. A matéria não se confunde com a forma dos objetos, mas é algo amorfo, ao mesmo tempo pré-objetivo e pré-subjetivo. A experimentação, por sua vez, não é subjetiva, mas a condição de constituição tanto do sujeito quando do mundo conhecido. Dessa perspectiva, sujeito e objeto são formações experimentais, inventadas (Kastrup, 2007, p.62).

O que a autora levanta atinge o cerne do próprio projeto e sujeito psicológico modernos, já que transfere a ideia de uma identidade fixa, de um eu que conhece, para uma subjetividade que é, antes de tudo, processo, devir, individuação, sendo o indivíduo resultado e não princípio. Há nele um regime pré-individual, que o mantém em devir permanente. A problematização, a dúvida, a inquietude movem e criam a cognição e o sujeito. Desse ponto de vista, a aprendizagem é um processo permanente de produção de subjetividade, isto é, de invenção de si.

Entretanto, como aponta Kastrup (2005), a educação tradicionalmente esteve a serviço do desempenho de tarefas e da solução de problemas, e mesmo as novas tecnologias vêm mantendo o projeto pedagógico baseado no modelo de transmissão de informação. Um modelo de trabalho que limita o alcance cognitivo e serve apenas à adaptação do sujeito ao meio, como alguns dos livros "pedagógicos” a que nos referimos anteriormente. Assim, certo modo de escrever para as crianças, em especial aquele apontado por Benjamin e Bettelheim, como mencionamos no início deste texto, responde à "política de recognição".

Façamos uma reflexão semelhante sobre os filmes produzidos para as crianças... Um certo modo de fazer filmes para as crianças também esteve e ainda é carregado de uma "política de recognição", especialmente quando se trata de pensar na relação do cinema com a educação. Precisamos identificar essas práticas (e criar novas), se almejamos transpor os limites instituídos por ela.

Quais práticas pedagógicas são capazes de produzir uma política cognitiva da invenção e não mais da recognição? Quais filmes perturbam a cognição, ao invés de “informá-la”? Quais filmes se alinham com o conceito de uma aprendizagem inventiva, capaz de abranger a problematização, de acolher um estado de suspensão, de 
inacabamento, de abertura, de inesperado, de imprevisível?

Nas palavras de Kastrup (2005): "O desafio da implementação dessa política é conceber práticas que viabilizem o desencadeamento de processos de problematização que não se esgotem ao encontrar uma solução" (p.1282).

\section{Cinema e aprendizagem: o lugar do pedagógico e (as) novas possibilidades}

Como vimos, a possibilidade de aprender com as imagens do cinema foi desde muito cedo explorada. 0 cinema inaugurou um novo gênero de memória, uma outra forma de linguagem, uma outra relação com a técnica, com o ensino, outro modo de contar e escrever a História. Como diz Carrière (2006), "gostando disso ou não, aceitando-o ou não, nossa visão do passado e talvez até nosso sentido de História nos chegam agora, principalmente, através do cinema" (p.60).

Duarte (2009) reconhece que o cinema é até hoje um instrumento precioso para ensinar valores, crenças, visões de mundo, fatos históricos. 0 cinema, complementa Fresquet (2009), aproxima o outro no tempo e no espaço - conhecemos paisagens, culturas, costumes de outros países e épocas -; com ele conhecemos melhor e mais profundamente a nós mesmos. A sétima arte proporciona um encontro com a alteridade, como diz o cineasta francês Alain Bergala (2008).

Essas são potências que hoje já parecem inquestionáveis. Mas, para acessar práticas que visem a uma "política cognitiva da invenção", é necessário tomar o cinema para além de um instrumento didático: é mister contextualizá-lo como produção cultural e artística, como uma obra em si mesma (Bergala, 2008; Fresquet, 2009, 2013; Leandro, 2001, 2010). De fato, o cinema pode ser tomado como um excelente instrumento de percepção de si e do outro, assinala Migliorin (2013), mas essencialmente por meio das decisões mais básicas que os cineastas precisam fazer para seus filmes existirem.

Isso implica conhecer e recolher informações sobre o filme, seu contexto de criação e seu realizador. Atitude que influencia diretamente o modo como vemos os filmes, como interagimos com eles e como nos afetam. Afirma Bill Nichols (1991), crítico do cinema documental:

0 que os filmes têm a dizer acerca da condição humana ou acerca de temas da atualidade não pode ser separado de como o dizem, como a forma de dizê-los nos emociona e nos afeta, como nos comprometemos com uma obra, e não com uma teoria da mesma (p.18). 
Nesse sentido, Pires (2011) ressalta o rigor estilístico e poético (de vanguarda) que diretores como Humberto Mauro ${ }^{4}$ e Joaquim Pedro de Andrade 5 imprimiram em seus filmes, no que pode ser considerado a segunda fase do Instituto Nacional de Cinema Educativo (INCE) no final dos anos 40. Com domínio de modernas técnicas da linguagem cinematográfica, uma montagem sofisticada e a diluição das fronteiras ficção-realidade, esses diretores conseguiram promover em seus filmes um deslocamento poético que rompia com a onisciência documental e com os didatismos.

Entretanto, ressalta a autora, apesar da sofisticação linguística, esse cinema não foi tomado - educativamente - a partir de sua própria estrutura, pois o pedagógico concentrava-se na mensagem transmitida, sobretudo, pelo tema. Leandro (2001) nos esclarece a questão, assinalando que imagens em movimento, luz, cores, ritmos, sons, ilusão de volumes, profundidades, texturas, não constituíam para a educação um objeto de estudo em si; e assim permaneceram até hoje.

Muitos filmes considerados educativos são, assim, classificados exclusivamente a partir do assunto que veiculam. Na maioria dos casos se trata de filmes cujos temas possuem um diálogo com o currículo escolar ou transmitem uma moral, ao molde dos livros infantis, ensinando uma virtude ou um comportamento que as crianças devem desenvolver no meio social. Entretanto, Leandro (2001) nos chama atenção para o fato de que "em muitos filmes e vídeos ditos educativos os planos ultrapassam raramente três ou quatro segundos e a ligação entre eles é feita por meio de efeitos visuais banalizados pela sua utilização excessiva e pouco criteriosa" (p.2).

0 que aconteceu foi que a instrumentalização das imagens fílmicas pouco considerou que não podemos separar o que os filmes dizem da forma como dizem e nos afetam. Não podemos separar o conteúdo dos filmes da linguagem cinematográfica. Falando em termos de uma "política de invenção", não podemos falar de transmissão de conteúdo, sem pensar no modo como essa transmissão produz nossa subjetividade, no modo como ela, a própria imagem, nos inventa. Assim, nos dizeres de Leandro (2001), é preciso pensar numa pedagogia da própria imagem e não mais em uma imagem pedagógica, se queremos nos comprometer com uma nova política.

4. Humberto Mauro é considerado um dos maiores cineastas da história do cinema brasileiro, tendo produzido durante seu tempo no INCE mais de 300 filmes, especialmente em parceria com Roquette Pinto. A velha a fiar (Mauro, 1964) é uma das obras analisadas pela autora. Neste curta metragem de sete minutos os ciclos vida e morte são trabalhados de modo alternado e poético. 0 filme é considerado ainda o primeiro videoclipe brasileiro. Retirado de: http://www.youtube.com/watch?v=JzCMGI7VCv8

5. O poeta do castelo (Joaquim Pedro de Andrade, 1959) é um curta metragem, obra-prima do cineasta. Um documentário nada convencional sobre Manuel Bandeira, roteirizado e "interpretado" pelo próprio poeta, ainda nos dias de hoje oferece recursos inovadores para uma linguagem documental no cinema. 0 filme e seu diretor são considerados precursores do cinema novo. Filme disponível em: http://www.youtube.com/watch?v=bJmboP4953Y 
A preocupação restrita ao conteúdo, às histórias, à moral do filme e a sua (boa ou má) influência na educação das crianças negligenciou o efeito que as próprias imagens, com sua estética e sua ética, que pensa e faz pensar, imprimem em nossa subjetividade. 0 cinema na educação e sua relação com a aprendizagem, isto é, com o que se aprende com ele, historicamente responderam à "política de recognição": sempre foram reduzidos ao acúmulo de informações que o filme seria capaz de transmitir e ao que o aluno seria capaz de reter.

Leandro (2001) alerta: "O desinteresse pela ontologia desse novo objeto [a imagem] do qual a educação se apropria tem levado a uma espécie de democratismo visual onde todas as imagens se equivalem, desde que a intenção pedagógica seja assegurada" (p.29).

Para verificar isso, Duarte (2009) coordenou uma pesquisa para conhecer a experiência das crianças com o cinema (o que veem, como veem filmes, quantos veem, quando, com quem, do que gostam e não gostam e por quê). A pesquisadora chegou a uma compreensão sobre o gosto infantil, que nomeou "mais do mesmo", isto é, uma pasteurização do gosto pelo acesso exclusivo a formatos muito semelhantes de quase uma única fonte cultural - a estadunidense. Segundo ela, a exposição das crianças a uma filmografia homogênea e hegemônica impede que percebam diferenças entre obras cinematográficas com propostas de linguagens (narrativas, rítmicas, estéticas, éticas) completamente diferentes entre si, o que as torna incapazes de formular uma avaliação qualitativa sobre o que veem.

A riqueza e a diversidade de experiências com que temos contato durante a infância têm impacto especial na nossa imaginação e atividade criadora. Segundo Vigotski (2009), o somatório de nossas experiências com o real fica guardado na memória e é recombinado pela imaginação, que cria o que não existe. A partir de elementos reais, vividos com o mundo, o homem recolhe material - experiências, que, recombinadas pela imaginação, geram um produto novo. É assim que o irreal (a partir do real) se torna, então, realidade, e o novo é capaz de surgir. Ao retornar para o mundo, esse novo criado altera, então, o real.

Como vimos com Kastrup (2007), o sujeito cria algo novo a partir daquilo que foi cultivado na cognição e (re)cria também nesse exercício a si mesmo. E não apenas aquilo que nós conhecemos pessoalmente é elemento para a imaginação e a invenção: a experiência que os outros nos contam, os livros que lemos, os filmes a que assistimos, também são arquivados em nossa memória e servem de elemento para 
ela. Assim, pensar a quais filmes as crianças assistem nos traz, portanto, uma dimensão estética, que é também política, pois diz respeito à manutenção ou não de uma determinada hegemonia naquilo que se vê, sente, fala, inventa e circula.

Afirma Rancière (2009) que existe uma estética na base da política, no sentido de que a política se ocupa do que vemos e do que pode ser visto; se ocupa do que pode ser dito sobre o que é visto; se ocupa de quem tem competência para ver e dizer sobre o que vê; se ocupa das propriedades do espaço e das possibilidades do tempo; se ocupa dos movimentos dos corpos, das funções da palavra, das repartições do visível e do invisível.

Assim, todo filme afirma e constrói uma determinada subjetividade, e é preciso saber a qual política cognitiva ele serve. "Trata-se, nesse regime, de saber no que o modo de ser das imagens concerne ao ethos, à maneira de ser dos indivíduos e das coletividades", afirma Rancière (2009, p.29).

Bergala (2008) orienta que, para suplantarmos a relação utilitarista com o cinema, é preciso "aceitar a alteridade do encontro artístico e deixar a necessária estranheza da obra de arte fazer seu lento caminho por si mesma” (p.34). Não devemos ter medo de exibir para as crianças filmes que não ofereçam uma solução fechada; filmes que gerem conflitos cognitivos e que as deixem maturar a invenção dos problemas. Não devemos ter medo dos finais não felizes. Além disso, não é preciso explicar nada previamente à criança: ela mesma constrói sua íntima e pessoal relação com a obra. É preciso confiar nelas.

O crítico francês considera que alguns filmes têm na infância um momento mais adequado para serem vistos, exatamente por estarem um tempo à frente da consciência infantil. Os filmes provocam nas crianças um trabalho existencial, "na surdina", quase ao modo de um conto de fadas, que muitas vezes eclodirá apenas anos depois, estando em devir. "Os devires são experiências novas, inéditas, que nos colocam em contato com a alteridade do mundo e da própria cognição” (Kastrup, 2005, p.1284).

Assim, superar a aprendizagem que se fundamenta na solução de problemas, em direção à “aprendizagem inventiva” que nos apresentou Kastrup $(2005,2007)$, implica promover o encontro da criança com um cinema que cause uma espécie de falta de ar, uma apneia de compreensão racional do que se vê, para que se experimente um vazio, uma incompletude, uma rejeição, e se aceite ver as coisas com sua parte de enigma, antes de sobrepor-lhes palavras e sentidos. Para a construção dessa nova política cognitiva, as crianças precisam conviver com as dúvidas, com o estranha- 
mento, com as perguntas sem respostas que alguns filmes despertam. Devem experimentar o não saber de obras cuja linguagem, montagem, tempo que lhes são menos familiares provocam. Variadas narrativas, outros ritmos, sentimentos, emoções, poesias, construções formais, de personagens e estéticas, precisam habitar o cinema infantil. A presença mais forte do silêncio e planos longos que seduzem o telespectador, deixando-o a esperar as imagens surgirem na tela podem habitar as produções infantis, para que se choquem com o imediatismo cinematográfico e pedagógico ao qual estão acostumadas.

Fresquet (2013) defende a diversificação do gosto pela escolha e exibição de filmes que produzam certo estranhamento, que gerem uma reação inicial, mesmo que frustrem as expectativas das crianças de apreciar o que comumente assistem nos cinemas de shoppings e na TV. Leandro finaliza (2001):

0 que se espera então de uma práxis do audiovisual na educação é uma contrapartida a essa estética comercial, ou seja, uma produção de imagens que considere o tempo da reflexão, da assimilação do saber, da consolidação da memória e que, assim fazendo, nos descortine o mistério da realização plástica de uma moral, de uma ética (p.34).

\section{Considerações finais}

Afinal, o que se aprende com o cinema?

Da discussão que colocamos, o que surge como uma questão maior não é o uso das artes literária ou cinematográfica para crianças como uma ferramenta pedagógica, mas a negligência de um outro pedagógico presente nelas. Ao criarmos uma denominação de cinema educativo ou qualquer prática, ação, gesto, objeto educativo, criamos, ao mesmo tempo, a ideia de que algo não é educativo.

A palavra "educativo" se popularizou como uma ação que traz em si uma intencionalidade educativa, com uma autoridade superior às supostas "não educativas". Com isso, o suposto "não educativo" acabou sendo subestimado, em termos da influência que tem sobre nós, adultos e crianças. Assim, a pergunta que devemos fazer diante de um filme endereçado às crianças não deve ser se este é ou não educativo, mas a qual política educativa ele serve. Porque, com certeza, serve a alguma.

Se as imagens trazem em si uma pedagogia própria, as crianças aprendem com elas um mundo inteiro - , com seu ritmo, com sua velocidade, com sua forma de enlaçar um sentimento e/ou um acontecimento a outro. A linguagem cinematográfi- 
ca, nos ensina Eisenstein (2002), é uma expressão do pensamento cinematográfico. Mas a apropriação pedagógica dos filmes tradicionalmente se ancorou em seus conteúdos, ignorando, afirma Leandro (2001), que as imagens possuem uma pedagogia intrínseca: pensam e fazem pensar por si sós; “uma imagem ensina na medida em que ela, tanto do ponto de vista formal quanto de conteúdo, veicula um pensamento, encorajando assim o pensamento no espectador" (p.6). 0 modo como as imagens nos falam constrói nossa subjetividade perceptiva, temporal, rítmica e espacial do mundo.

Bergala (2008) considera curioso que a educação tenha tanta preocupação com a veiculação ideológica do cinema e o mesmo não aconteça em relação à educação artística do homem.

Pensar que o cinema pode ser educativo é entender o cinema como um vetor de ideologia antes de tudo, isto é, o cinema pode ser perigoso, o perigo ideológico. 0 medo de valores nefastos que o cinema pode ser portador (violência, racismo etc.) mas não se tem medo da mediocridade e da nulidade artística (p.45).

Pauta permanente de discussões entre educadores, psicólogos, pais e profissionais da mídia é a relação da criança com as imagens e o audiovisual, concentrando-se na influência que seus conteúdos exercem sobre os desejos e os pensamentos infantis, ou ainda na preocupação com seus teores pedagógicos e morais. Há também pesquisas sobre as transformações narrativas e linguísticas advindas da força das imagens, das novas tecnologias e os consequentes desafios para a escola hoje, construída sobre os pilares modernos da introspecção e do texto escrito.

Essas são discussões importantíssimas, mas deixam de fora a relação das crianças com o cinema como bem cultural e como marca de um gesto de criação (Bergala, 2008): dimensões igualmente educativas, constitutivas do homem e sua subjetividade. A preocupação com as imagens e com o audiovisual pouco reflete a intenção de democratizar o acesso a diferentes filmes sob pontos de vista estéticos e técnicos, rítmicos, sonoros, de movimento, montagem, som, luz, fotografia, enquadramentos, cores, disposição - enfim, as escolhas dos cineastas são ignoradas e naturalizadas, não são tomadas como construções de uma realidade, a realidade da arte cinematográfica. E com isso advém um problema crucial para a educação: uma realidade que não é construída não pode ser transformada. Educação para quê? 
O que queremos, quando exibimos e produzimos filmes para as crianças? 0 que a criança aprende, quando assiste a um filme? Todo filme infantil é um filme educativo? O que um filme precisa ter, ser, mostrar, fazer, para ser classificado como um filme educativo? Onde se encontra, afinal, o caráter pedagógico dos filmes?

Restituir a dimensão constitutiva (ou educativa) do humano em todos os cinemas (tradicionalmente chamados de educativos ou não) é condição para o exercício da democracia social, política, econômica e psicológica. As imagens, o pedagógico e o educativo nos colocam, fundamentalmente, questões éticas, no que diz respeito a produção, seleção e exibição dos filmes infantis. Esperamos, com este texto, ter dado vida e movimento a algumas questões que não se esgotam aqui, mas que devem estar sempre presentes quando pensamos a criança, o cinema e as imagens. 


\section{Referências bibliográficas}

Ariès, P. (1981). História social da criança e da família (2a ed.). Rio de Janeiro: Zahar.

Benjamin, W. (2002a). Livros infantis velhos e esquecidos. In W. Benjamin, Reflexões sobre a criança, o brinquedo e a educação. São Paulo: Duas Cidades.

Benjamin, W. (2002b). 0 ensino de moral. In W. Benjamin, Reflexões sobre a criança, o brinquedo e a educação. São Paulo: Duas Cidades.

Bergala, A. (2008). Hipótese-cinema: pequeno tratado de transmissão do cinema dentro e fora da escola. Rio de Janeiro: Booklink; CINEAD-LISE-FE/UFRJ.

Bettelheim, B. (1980). A psicanálise dos contos de fadas. Rio de Janeiro: Paz e Terra.

Brasil. (1932). Decreto $n^{\circ} 21.240$ de 4 de abril de 1932. Nacionaliza o serviço de cen sura dos filmes cinematográficos, cria a Taxa Cinematográfica para a educação popular e dá outras providências. Rio de Janeiro, RJ. Acessado em (novembro de 2013), de http://www.ancine.gov.br/legislacao/decretos/decreto-n-21240-de-4de-abril-de-1932.

Carrière, J.-C. (2006). A linguagem secreta do cinema. Rio de Janeiro: Nova Fronteira.

Duarte, R. (2009). Cinema e educação. Belo Horizonte: Autêntica.

Eisenstein, S. (2002). A forma do filme. Rio de Janeiro: Zahar.

Fresquet, A. (Org.). (2009). Aprender com as experiências do cinema. Rio de Janeiro: Booklink; CINEAD-LISE-FE/UFRJ.

Fresquet, A. (2013). Cinema e educação: reflexões e experiências com estudantes de educação básica, dentro e "fora" da escola (1a ed.) Rio de Janeiro: Autêntica.

Kastrup, V. (2005, setembro/dezembro). Políticas cognitivas na formação do professor e o problema do devir-mestre. Educação e Sociedade, 26(93), 1273-1288.

Kastrup, V. (2007). A invenção de si e do mundo: uma introdução do tempo e do coletivo no estudo da cognição. Belo Horizonte: Autêntica.

Leandro, A. (2001, maio/setembro). Da imagem pedagógica à pedagogia da imagem. Comunicação e Educação,7(21), 29-36. Retirado em novembro de 2013 de: http:// www.revistas.usp.br/comueduc/article/view/36974/39696.

Leandro, A. (2010, julho/dezembro). Posfácio - Uma questão de ponto de vista. Revista Contemporânea de Educação, 5(10).

Migliorin, C. (2013). Prefácio. In A. Fresquet, Cinema e educação: reflexões e experiências com estudantes de educação básica, dentro e "fora" da escola (1 1 a ed.). Rio de Janeiro: Autêntica. 
Nichols, B. (1991). The domain of documentary. In B. Nichols, Representing reality: issues and concepts in documentary. Indianapolis: Indiana University Press.

Pires, E. G. (2011). Cinema e educação: o deslocamento poético do olhar na construção do conhecimento. Recuperado em novembro de 2013, de http://www.rua.ufscar. $\mathrm{br} / \mathrm{site} / \mathrm{p}=3823$.

Rancière, J. (2009). A partilha do sensível: estética e política. São Paulo: EXO experimental org; Editora 34.

Saliba, M. E. F. (2003). Cinema contra cinema: o cinema educativo de Canuto Mendes (1922-1931). São Paulo: Annablume; FAPESP.

Schvarzman, S. (2004). Humberto Mauro e as imagens do Brasil. São Paulo: Editora Unesp.

Vargas, G. (1934). Cinema nacional: elemento de aproximação dos habitantes do país. Discurso pronunciado na manifestação promovida pelos cinematografistas em 25 de junho de 1934. Biblioteca da Presidência da República. Recuperado em janeiro de 2014, de http://www.biblioteca.presidencia.gov.br/ex-presidentes/ getulio-vargas/discursos-1/1934/04.pdf.

Vigotski, L. (2003). A formação social da mente (6a ed.). São Paulo: Martins Fontes.

Vigotski, L. (2009). Imaginação e criação na infância. São Paulo: Ática.

Submetido à avaliação em 20 de fevereiro de 2014; aprovado para publicação em 25 de setembro de 2014. 